\title{
Computed tomography evaluation of the normal craniocervical junction craniometry in 100 asymptomatic patients
}

\author{
Ulysses C. Batista, MD, Andrei F. Joaquim, MD, PhD, Yvens B. Fernandes, MD, PhD, \\ Roger N. Mathias, MD, Enrico Ghizoni, MD, PhD, and Helder Tedeschi, MD, PhD \\ Department of Neurology, State University of Campinas (UNICAMP), Campinas, São Paulo, Brazil
}

\begin{abstract}
OBJECT Most of the craniometric relationships of the normal craniocervical junction (CCJ), especially those related to angular craniometry, are still poorly studied and based on measurements taken from simple plain radiographs. In this study, the authors performed a craniometric evaluation of the CCJ in a population without known CCJ anomalies. The purpose of the study was to evaluate the normal CCJ craniometry based on measurements obtained from CT scans.
\end{abstract}

METHODS The authors analyzed 100 consecutive CCJ CT scans obtained in adult patients who were admitted at their tertiary hospital for treatment of non-CCJ conditions between 2010 and 2012. A total of 17 craniometrical measurements were performed, including the relation of the odontoid with the cranial base, the atlantodental interval (ADI), the clivus length, the clivus-canal angle (CCA) - the angle formed by the clivus and the upper cervical spine, and the basal angle.

RESULTS The mean age of the 100 patients was 50.6 years, and the group included 52 men (52\%) and 48 women $(48 \%)$. In 5 patients (5\%), the tip of the odontoid process was more than $2 \mathrm{~mm}$ above the Chamberlain line, and in one of these 5 patients ( $1 \%$ of the study group). it was more than $5 \mathrm{~mm}$ above it. One patient had a Grabb-Oakes measurement above $9 \mathrm{~mm}$ (suggesting ventral cervicomedullary encroachment). The mean ADI value was $1.1 \mathrm{~mm}$. The thickness of the external occipital protuberance ranged from 7.42 to $22.36 \mathrm{~mm}$. The mean clivus length was $44.74 \mathrm{~mm}$, the mean CCA was $153.68^{\circ}$ (range $132.32^{\circ}-173.95^{\circ}$ ), and the mean basal angle was $113.73^{\circ}$ (ranging from $97.06^{\circ}-133.26^{\circ}$ ).

CONCLUSIONS The data obtained in this study can be useful for evaluating anomalies of the CCJ in comparison with normal parameters, potentially improving the diagnostic criteria of these anomalies. When evaluating CCJ malformations, one should take into account the normal ranges based on CT scans, with more precise bone landmarks, instead of those obtained from simple plain radiographs.

http://thejns.org/doi/abs/10.3171/2015.1.FOCUS14642

KEY WORDS craniometry; craniocervical junction; CT scan; relationship; normal

$\mathrm{T}$ HE majority of the articles related to spinal alignment evaluate the center of gravity of the sagittal vertical axis, pelvic incidence, cervical and lumbar lordosis, and thoracic kyphosis. ${ }^{7,18,23}$ However, the parameters of the normal craniometric relationships of the craniocervical junction (CCJ), especially those for angular craniometry, are still poorly studied and historically based on measurements taken from plain radiographs. ${ }^{17}$ If compared with plain radiographs, where bone structures are superimposed, the use of modern diagnostic imaging methods for evaluation of all CCJ diseases, such as CT scan with reconstruction or MRI, would probably result in different craniometric measurements. ${ }^{3,5,17}$ Moreover, most of the studies of CCJ craniometry were performed in patients with congenital malformations-Chiari malformation $(\mathrm{CM})$ and/or basilar invagination (BI)..$^{1,13,14}$

The craniometric parameters of the $\mathrm{CCJ}$ are of paramount importance to understand and propose adequate treatments for the different diseases that affect the region. For instance, $\mathrm{BI}$ is a radiological finding diagnosed, as proposed by Chamberlain, ${ }^{3,22}$ when the tip of the odontoid process is located above a line from the posterior margin of the hard palate to the opisthion. ${ }^{3,22}$ However, different thresholds, such as 2 or $5 \mathrm{~mm}$ above the line, have been proposed for diagnosis of this condition. ${ }^{8,21}$ Accurate CTbased studies on the normal craniometry of the craniocer-

ABBREVIATIONS ADI = atlantodental interval; $C C A$ = clivus-canal angle (angle formed by a line extending from the surface of the clivus and a line extending from the inferodorsal portion of the $\mathrm{C}-2$ body); $\mathrm{CCJ}=$ cranicervical junction; $\mathrm{CM}=$ Chiari malformation; $\mathrm{EOP}=$ external occipital protuberance; $\mathrm{FM}=$ foramen magnum.

SUBMITTED September 6, 2014. ACCEPTED January 21, 2015.

INCLUDE WHEN CITING DOI: 10.3171/2015.1.FOCUS14642.

DISCLOSURE The authors report no conflict of interest concerning the materials or methods used in this study or the findings specified in this paper. 
vical junction can be helpful in improving the precision of such diagnosis criteria and improving the classification of $\mathrm{CCJ}$ anomalies.

In light of the above considerations, we performed a craniometrical evaluation of an asymptomatic population, with the purpose of gathering information on the normal 3D CT parameters of the CCJ in asymptomatic individuals.

\section{Methods}

After obtaining institutional review board approval, we evaluated 100 consecutive CCJ CT scans obtained in adult patients who were admitted to our tertiary hospital for treatment of non-CCJ conditions between 2010 and 2012.

In order to be included in the study, patients had to be older than 17 years and have undergone a complete CT scan of the CCJ for causes other than an investigation of a CCJ malformation or congenital anomaly. Patients were excluded if their radiological examinations were not sufficient for the proposed measurements, if they had undergone only a dynamic CT scan that would preclude some of the measurements, if they were undergoing mechanical ventilation at the time of the CT scan, or if they were known to have pathological conditions of the CCJ (such as $\mathrm{CM}, \mathrm{BI}$, rheumatoid arthritis, or upper cervical spine trauma).

\section{CT Scan Measurements}

Measurements were performed by 2 researchers (U.C.B. and R.N.M.) working together and were recorded upon agreement. The studies were obtained on a 64-row multidetector CT (MDCT) scanner (Aquilion 64, Toshiba Medical System), using a rotation time of $600 \mathrm{msec}$, tube voltage of $120 \mathrm{kV}$, and tube current of $120-250 \mathrm{~mA}$. The images were reconstructed into 0.5 -mm-thick slices with space between slices of $0.3 \mathrm{~mm}$. All scans were analyzed on a present bone window setting: length $300 \mathrm{HU}$ and width $2500 \mathrm{HU}$.

The images were assessed on the radiological workstation center, and all the measurements were performed using the PACS (picture archiving and communication system) electronic system. The following measurements were obtained:

1) The distance from the tip of the odontoid to the Chamberlain line was determined as follows. A line was drawn from the posterior hard palate to the tip of the opisthion (the Chamberlain line) on a sagittal CT image (Fig. 1A). A perpendicular line was then traced through the tip of the odontoid, and the length of this line was recorded as well as whether the odontoid tip was above or below the Chamberlain line. ${ }^{3,15}$

2) The amount of ventral cervicomedullary encroachment by the odontoid - the measurement proposed by Grabb-Oakes - measured in a sagittal CT image as the distance to a perpendicular line traced from the most posterior region of the dura mater covering the dens to the line that goes from the inferior surface of the basion to the posterior inferior aspect of the $\mathrm{C}-2$ vertebral body 9,11 (Fig. 1B).

3) The atlantodental interval (ADI) was measured as the distance between the posterior border of the anterior
$\mathrm{C}-1$ arch and the anterior margin of the odontoid process on a midline sagittal CT image (Fig. 1C).

4) The anteroposterior and latero-lateral diameters of the foramen magnum (FM) were measured as the greatest distance between the anterior and posterior rims of the FM and the greatest distance from its left lateral surface to its right lateral surface of the $\mathrm{FM}^{4}$ (Fig. 1D and $\mathrm{E}$, respectively).

5) The thickness of the external occipital protuberance (EOP; the distance between the inner and outer surfaces of the EOP) was measured on a midline sagittal CT image, as was the thickness of the occipital crest 1 $\mathrm{cm}$ below the EOP (Fig. 1F and G, respectively).

6) The height of the C-1 lateral masses (right and left) was measured on sagittal CT images. The length of a line centered in the atlas lateral mass from the midpoint of the superior articular surface to the midpoint of its inferior articular surface of the lateral mass was measured on both $\operatorname{sides}^{2}$ (Fig. 2A).

7) The occipital condyle height (right and left) was measured on sagittal CT images as the length of a line centered in the occipital condyle between the midpoint of the superior articular surface and the midpoint of its inferior articular surface (Fig. 2B).

8) The clivus length was measured on a midline sagittal CT image as the distance between the top of the dorsum sellae and the basion ${ }^{6}$ (Fig. 2C).

9) Distance between the internal acoustic meati was measured on an axial CT image as the length of a straight line drawn between the left and right internal acoustic meati ${ }^{16}$ (Fig. 2D).

10) The height of the crista galli was measured on a midline sagittal image as the maximum distance from the top of the crista galli to its base (Fig. 2E).

11) The distance between the crista galli and anterior tuberculum sellae was estimated on a midline sagittal image as the distance between the posterior edge of the crista galli to the region of the anterior tuberculum sellae, until the end of the planum sphenoidale (Fig. 2F).

12) The clivus-canal angle (CCA; angle formed by a line extending from the surface of the clivus and a line extending from the inferodorsal portion of the $\mathrm{C}-2$ body) was measured as the angle at the intersection of a line extending from the inferior one-third of the clivus and a line extending from the inferodorsal portion of the $\mathrm{C}-2$ vertebral body to the superodorsal part of the dens ${ }^{1}$ (Fig. 2G).

13) The basal angle ${ }^{14}$ was measured as the angle formed by an intersection of the line from the nasion to the dorsum sellae and a line from the dorsum sellae to the basion $^{1}$ (Fig. $2 \mathrm{H}$ ).

The results of all these measurements are presented in detail with descriptive statistics, reported as means, medians, ranges, and standard deviations. The normal range for the CCJ parameters was defined as the values within 2 standard deviations of the mean $( \pm 2 \mathrm{SD})$, representing approximately $95 \%$ of patients in a normal distribution.

\section{Results}

The craniometric measurements were obtained in 100 asymptomatic patients with a mean age of 50.6 years (SD 


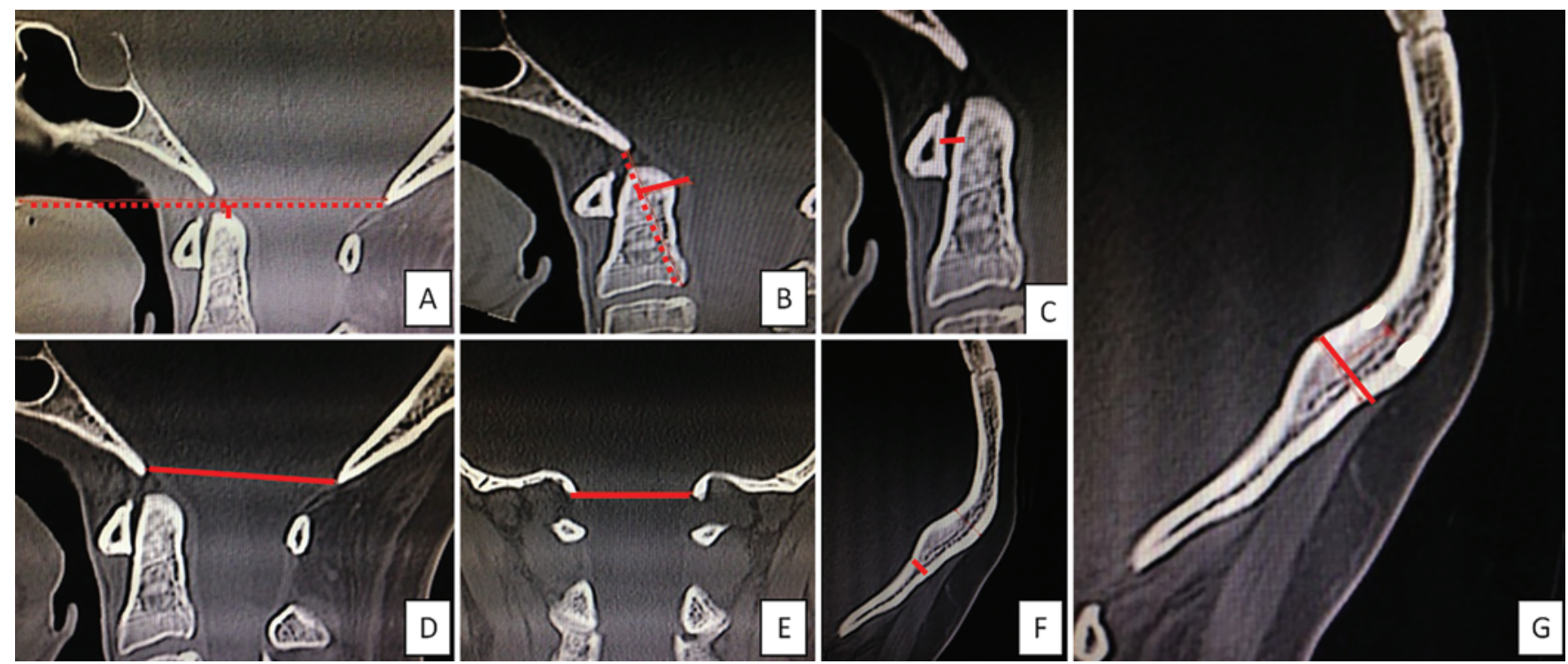

FIG. 1. A: The distance from the tip of the odontoid to the Chamberlain line. B: Amount of ventral cervicomedullary encroachment by the odontoid-the measured proposed by Grabb-Oakes. C: The ADI. D and E: The anteroposterior and latero-lateral FM diameter. F: The EOP thickness. G: The thickness of the occipital crest $1 \mathrm{~cm}$ below the EOP.

18.80, median 51 years, range $18-82$ years). The group included 52 men $(52 \%)$ and 48 women $(48 \%)$. A total of 85 patients $(85 \%)$ had a CT scan for evaluation of head trauma. Fifteen patients underwent CT screening for other conditions, such as stroke, syncope, headache, and epilepsy investigation.

The mean distance of the tip of the odontoid process from the Chamberlain line was $-1.5 \mathrm{~mm}$ (below the line; median of $-1.8 \mathrm{~mm}, \mathrm{SD} 2.2$ ), ranging from -7.6 (below the line) to $+5.2 \mathrm{~mm}$ (above the line). In 5 patients $(5 \%)$, the tip of the odontoid process was more than $2 \mathrm{~mm}$ above the Chamberlain line, and in one of these 5 patients (1\% of the overall group), the tip of the odontoid process was more than $5 \mathrm{~mm}$ above the Chamberlain line.

The mean distance of the dura mater from the line that goes from the inferior surface of the basion to the inferior aspect of the C-2 vertebral body was $6.7 \mathrm{~mm}$ (SD $1.0 \mathrm{~mm}$, median $6.5 \mathrm{~mm}$, range $4.2-10.2 \mathrm{~mm})$. Just 1 patient $(1 \%$ of the group) had a measurement above $9 \mathrm{~mm}$ : $10.2 \mathrm{~mm}$.

All measurements obtained are summarized in Table 1.

\section{Discussion}

In the present study, we have shown the craniometrical relationships of the normal CCJ based on CT scan measurements performed in 100 adult patients without known CCJ disease. The normal ranges, as presented in Table 1 , are important for improving the diagnostic criteria of many CCJ congenital or acquired diseases.

Rojas et al. assessed normal anatomical relationships of the CCJ on CT scans obtained in 200 patients who underwent imaging as part of a trauma protocol and were
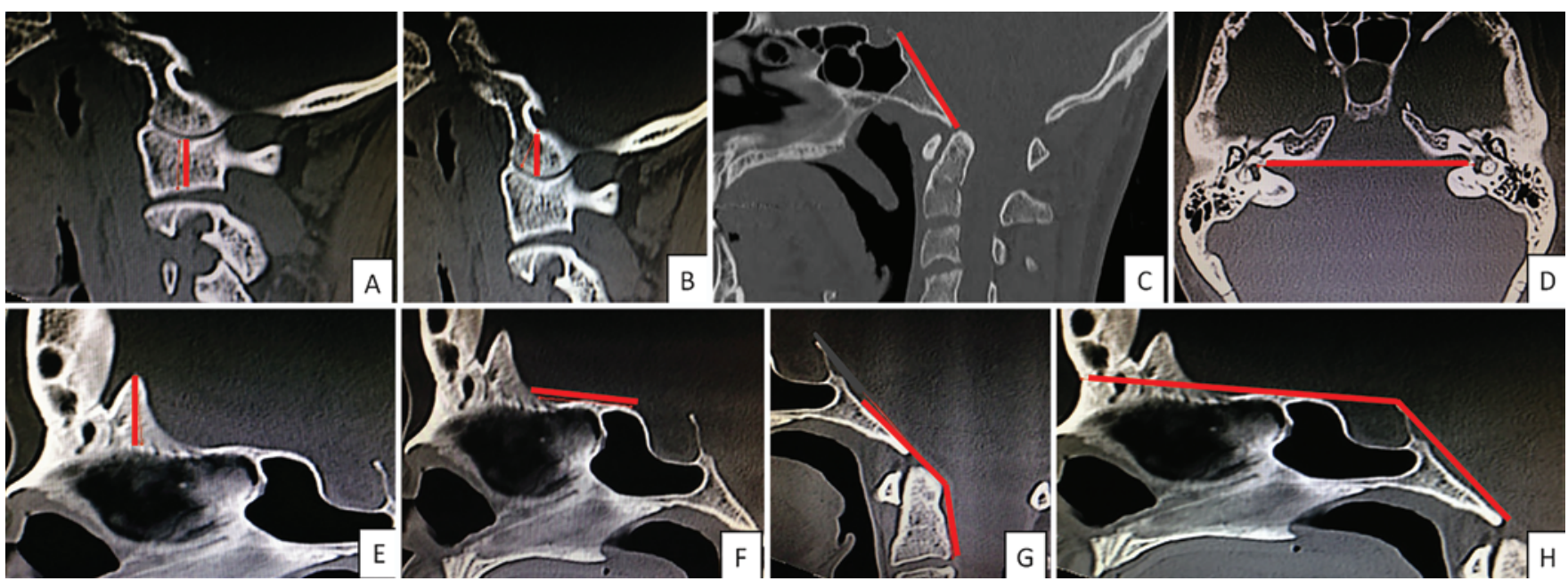

FIG. 2. A: Height of C-1 lateral mass. B: Occipital condyle height. C: Clivus length. D: Distance between the internal acoustic meati. E: Height of the crista galli. F: Distance between the crista galli and anterior tuberculum sellae. G: Clivus canal angle. H: Basal angle. 
found to have no osseous or soft tissue abnormality. The values differed significantly from the classic values based on standard plain radiographs. ${ }^{19}$ The authors reported that 95\% of their patients had an ADI less than $2 \mathrm{~mm}$, smaller than the historical value of $3 \mathrm{~mm}$ previously reported in studies from the 1960s as the normal upper limit. ${ }^{12}$ In our series, none of the 100 patients had an ADI of more than 2 $\mathrm{mm}$. Given that modern spinal surgery is mainly based on CT and MR images, it is our opinion that the normal upper superior limit of ADI in sagittal CT scan reconstruction should be $2 \mathrm{~mm}$. This change would probably affect the sensibility and the specificity of the CT scan in detecting many diseases, such as atlanto-axial instabilities.

In our series, the mean distance from the tip of the odontoid process to the line proposed by Chamberlain was $-1.55 \mathrm{~mm}$ (below the line). Of note, some patients had the tip of the odontoid $2 \mathrm{~mm}$ or even $5 \mathrm{~mm}$ above the Chamberlain line, both levels that have been proposed as diagnostic criteria for basilar invagination. ${ }^{8,21}$ Based on our findings, we could conclude that, due to anatomical variations, some asymptomatic individuals would have the diagnosis of basilar invagination (up to $5 \%$ of the patients in our series). ${ }^{8,21}$ Based on a normal distribution, the normal accepted range ( \pm 2 SD from the mean) of the distance of the tip of the odontoid process in our population was from $5.9 \mathrm{~mm}$ below to $2.9 \mathrm{~mm}$ above the Chamberlain line. Patients with the tip of the odontoid extending more than $2.9 \mathrm{~mm}$ past the Chamberlain line would be considered abnormal in our study population. When analyzing the amount of ventral cervicomedullary encroachment by the odontoid, a measurement proposed by Grabb et al., the mean distance from the most posterior region of the dura mater covering the tip of the odontoid process to the line that goes from the inferior surface of the basion to the inferior aspect of the C-2 body was $6.7 \mathrm{~mm}$, and only 1 asymptomatic patient had a value above $9 \mathrm{~mm}$ for this measurement (in that patient it was $10.2 \mathrm{~mm}$ ). ${ }^{9}$

The thickness of the EOP is important when planning craniocervical fixation using occipital screws and plating. The wide range of the EOP thickness (7.4-22.3 mm) implies that spinal implants should have a large variety of screw lengths to allow surgeons to place bicortical screws in the occipital crest. Of note, we had patients with just 2.9 $\mathrm{mm}$ of occipital thickness $1 \mathrm{~cm}$ below the EOP, a length not found in most of the commercially available spinal implant sets used for craniocervical fixation.

The clivus canal angle is depicted by the intersection of a line extending along the clivus intersecting and a line along the upper cervical spine. Measurements based on plain radiographs generally range from $150^{\circ}$ to $180^{\circ}$, and measurements smaller than $150^{\circ}$ have been reported to be associated with ventral spinal cord compression when smaller than $150^{\circ}$ on plain radiographs. ${ }^{22}$ However, the normal range was different in MRI studies. Botelho and Ferreira performed an evaluation of the clivus canal angle in 33 asymptomatic patients used as controls in a CCJ malformation study. The mean CCA obtained in that study was of $148^{\circ} \pm 9.8^{\circ}\left(\right.$ range $\left.129^{\circ}-179^{\circ}\right) .^{1}$ In our present study, the mean CCA in normal subjects was $153.6^{\circ} \pm 7.6^{\circ}$ (range $132.3^{\circ}-173.9^{\circ}$ ). Thus, the range of CCA values obtained from MRI and CT scans of asymptomatic patients appears to be substantially larger than the published values based on plain radiographs. ${ }^{22}$ In our series, 24 patients (24\%) had a CCA of less than $150^{\circ}$.

The basal angle measured in the present study was formed by an intersection of the line that goes from the nasion to the dorsum sellae and a line from the dorsum sellae to the basion. ${ }^{14}$ Our mean basal angle was $113.7^{\circ}$ (SD

TABLE 1. Craniocervical measurements performed in 100 individuals without known CCJ pathology using 3D CT reconstructions

\begin{tabular}{|c|c|c|c|c|c|c|}
\hline \multirow[b]{2}{*}{ Measurement } & \multirow[b]{2}{*}{ Mean } & \multirow[b]{2}{*}{ Median } & \multirow[b]{2}{*}{ SD } & \multicolumn{2}{|c|}{ Range } & \multirow[b]{2}{*}{ Normal Range* } \\
\hline & & & & From & To & \\
\hline Distance from tip of odontoid process to Chamberlain line $(\mathrm{mm})$ & $1.5 \dagger$ & $1.8 \dagger$ & 2.2 & 7.6 below & 5.2 above & 5.9 below to 2.9 above \\
\hline Amount of ventral cervicomedullary encroachment by odontoid (mm) & 6.7 & 6.5 & 1.0 & 4.2 & 10.2 & $4.7-8.7$ \\
\hline ADI & 1.1 & 1.1 & 0.3 & 0.1 & 2 & $0.5-1.7$ \\
\hline Anteroposterior diameter of FM (mm) & 33.9 & 33.8 & 2.7 & 25.9 & 40.6 & $28.5-39.3$ \\
\hline Latero-lateral diameter of FM (mm) & 28.2 & 27.7 & 2.6 & 22.1 & 36.4 & $23-33.4$ \\
\hline $\mathrm{EOP}(\mathrm{mm})$ & 14.0 & 14.3 & 2.6 & 7.4 & 22.3 & $8.8-19.2$ \\
\hline Thickness $1 \mathrm{~cm}$ below EOP $(\mathrm{mm})$ & 9.0 & 9.3 & 2.3 & 2.9 & 13.4 & $4.4-13.6$ \\
\hline Height of C-1 lateral mass, right (mm) & 10.4 & 10.3 & 1.1 & 8.2 & 13.5 & $8.2-12.6$ \\
\hline Height of C-1 lateral mass, left (mm) & 10.5 & 10.4 & 1.3 & 7.5 & 13.7 & $7.9-13.1$ \\
\hline Occipital condyle height, right (mm) & 10.4 & 10.0 & 1.8 & 7.0 & 18.0 & $6.8-14$ \\
\hline Occipital condyle height, left (mm) & 10.7 & 10.2 & 2.0 & 7.7 & 17.4 & $6.7-14.7$ \\
\hline Clivus length (mm) & 44.7 & 44.4 & 3.5 & 36.6 & 53.6 & $37.7-51.7$ \\
\hline Distance btwn both internal acoustic meati (mm) & 51.9 & 51.8 & 4.0 & 39.7 & 64.3 & $43.9-59.9$ \\
\hline Height of crista galli (mm) & 12.3 & 12.5 & 3.1 & 0 & 19.3 & $6.1-18.5$ \\
\hline Distance btwn crista galli \& anterior tuberculum sellae $(\mathrm{mm})$ & 29.2 & 29.3 & 3.3 & 21.9 & 35.9 & $22.6-35.8$ \\
\hline CCA & $153.6^{\circ}$ & $153.9^{\circ}$ & $7.6^{\circ}$ & $132.3^{\circ}$ & $173.9^{\circ}$ & $138.4-168.8^{\circ}$ \\
\hline Basal angle & $113.7^{\circ}$ & $112.0^{\circ}$ & $7.8^{\circ}$ & $97.0^{\circ}$ & $133.2^{\circ}$ & $98.1-129.3^{\circ}$ \\
\hline
\end{tabular}

\footnotetext{
* Values within 2 standard deviations $( \pm 2 \mathrm{SD})$ of the mean.

$\dagger$ Below the Chamberlain line.
} 
$7.8^{\circ}$, median $112.0^{\circ}$, range $97.0^{\circ}-133.2^{\circ}$ ). Koenigsberg and colleagues evaluated the normal basal angle of 200 adults using MRI and the same anatomical parameters (from the top of the dorsum sellae to the nasion and the basion); they obtained a mean value of $129^{\circ} \pm 6^{\circ} \cdot{ }^{14}$ Botelho and Ferreira reported that the $\mathrm{BA}$ ranged from $107^{\circ}$ to $132^{\circ}$ in their series of 33 asymptomatic patients (mean $119^{\circ} \pm 7.1^{\circ}$ ). They proposed that the diagnosis of platybasia (flattening of the skull base) should be made when the BA was above $133^{\circ}$. Of note, when the BA is measured using the top of the dorsum sellae, the literature described smaller values than those measurements made using the center of the sella. Smoker et al. proposed that the BA should always be less than $140^{\circ}$ when using the angle formed by the intersection of the nasion-tuberculum sellae line and the tuberculum sellae-basion line. As stated above, using the tuberculum sellae or the center of the sella turcica instead of the dorsum sellae would result in greater BA values than measurements performed using the top of the dorsum sellae. ${ }^{22}$

Considering the clivus length, measured from the top of the dorsum sellae to the basion, the mean length obtained value in our study was $44.7 \mathrm{~mm}$ (SD $3.5 \mathrm{~mm}$, median $44.4 \mathrm{~mm}$, range $36.6-53.6 \mathrm{~mm}$ ). Heiss et al. reported that the mean clivus length in 18 normal patients was 43.2 $\pm 3.5 \mathrm{~mm}$, compared with a mean of $38.6 \pm 3.4 \mathrm{~mm}$ in 48 patients with $\mathrm{CM}(\mathrm{p}<0.0001) .{ }^{10}$ The normal range for clivus length reported in our series is very similar to the normal range obtained by Heiss et al..$^{10}$ Dufton et al. also performed a comparative study of clivus length measured using midsagittal T1-weighted MR images obtained in 81 patients with $\mathrm{CM}$ and 107 patients considered controls. ${ }^{6}$ The clivus length was shorter in CM patients $(4.02 \pm 0.45$ $\mathrm{cm})$ than in the controls $(4.23 \pm 0.42 \mathrm{~cm})(\mathrm{p}=0.009)$. Also, the anteroposterior diameter in patients with $\mathrm{CM}$ was greater than in the control group. The mean anteroposterior diameter in the control group was $36.3 \pm 3.0 \mathrm{~mm}$ in that study (as compared with $33.9 \pm 2.7 \mathrm{~mm}$ in the present study).

Saralaya et al. performed a morphometrical anatomical study of 140 occipital condyles from 70 dry skulls. ${ }^{20}$ The average occipital condyle height was $10.2 \mathrm{~mm}$. Interestingly, our CT scan method of measurement of the condyle height was very comparable to the direct measurement in cadavers - we obtained an average $10.48 \mathrm{~mm}$ height for the right condyle height and $10.74 \mathrm{~mm}$ for the left one. On the other hand, the mean height of the C-1 lateral masses obtained in a study of 32 cadavers was $13.68 \pm 1.38 \mathrm{~mm}$, a value higher than ours (the mean height of the right and left C-1 lateral masses in our study was $10.4 \pm 1.1 \mathrm{~mm}$ and $10.5 \pm 1.3 \mathrm{~mm}$, respectively), suggesting that sagittal CT measurement of the atlas lateral mass height resulted in an underestimate.

Our study is limited by the lack of intra- and inter-reliability assessment for the presented CCJ measurements. Further studies addressing the reliability of CT scan measurement of the normal CCJ craniometry are necessary. Additionally, CCJ craniometry may be influenced by many other factors, such as patient race, sex, age, and height, among others. Our study did not address these issues, but they should be taken into account in future research in this field. Finally, we believe that the precise landmarks ob- tained with CT reconstructions should improve the reproducibility of CCJ craniometry compared with measurements obtained with simple plain radiographs.

\section{Conclusions}

We reported our results on normal craniometrical values obtained from modern 3D reconstructions in 100 asymptomatic individuals. These data can be useful for evaluating anomalies of the CCJ in comparison with normal parameters, potentially improving the diagnostic criteria of most anomalies. When evaluating CCJ malformations, surgeons should take into account the normal ranges based on CT scan instead of those obtained from plain radiographs.

\section{References}

1. Botelho RV, Ferreira ED: Angular craniometry in craniocervical junction malformation. Neurosurg Rev 36:603-610, 2013

2. Carvalho MF, Rocha RT, Monteiro JT, Pereira CU, Leite RF, Defino HL: Tomographic study of the atlas concerning screw fixation on lateral mass. Acta Ortop Bras 17:136-138, 2009

3. Chamberlain WE: Basilar impression (platybasia). A bizarre developmental anomaly of the occipital bone and upper cervical spine with striking and misleading neurologic manifestations. Yale J Biol Med 11:487-496, 1939

4. Chethan P, Prakash KG, Murlimanju BV, Prashanth KU, Prabhu LV, Saralaya VV, et al: Morphological analysis and morphometry of the foramen magnum: an anatomical investigation. Turk Neurosurg 22:416-419, 2012

5. Dolan KD: Cervicobasilar relationships. Radiol Clin North Am 15:155-166, 1977

6. Dufton JA, Habeeb SY, Heran MK, Mikulis DJ, Islam O: Posterior fossa measurements in patients with and without Chiari I malformation. Can J Neurol Sci 38:452-455, 2011

7. Lee SH, Son ES, Seo EM, Suk KS, Kim KT: Factors determining cervical spine sagittal balance in asymptomatic adults: correlation with spinopelvic balance and thoracic inlet alignment. Spine J [epub ahead of print], 2013

8. Goel A: Basilar invagination, Chiari malformation, syringomyelia: a review. Neurol India 57:235-246, 2009

9. Grabb PA, Mapstone TB, Oakes WJ: Ventral brain stem compression in pediatric and young adult patients with Chiari I malformations. Neurosurgery 44:520-528, 1999

10. Heiss JD, Suffredini G, Bakhtian KD, Sarntinoranont M, Oldfield EH: Normalization of hindbrain morphology after decompression of Chiari malformation Type I. J Neurosurg 117:942-946, 2012

11. Henderson FC, Wilson WA, Mott S, Mark A, Schmidt K, Berry JK, et al: Deformative stress associated with an abnormal clivo-axial angle: a finite element analysis. Surg Neurol Int 1:30, 2010

12. Hinck VC, Hopkins CE: Measurement of the atlanto-dental interval in the adult. Am J Roentgenol Radium Ther Nucl Med 84:945-951, 1960

13. Karagöz F, Izgi N, Kapíjcíjoğlu Sencer S: Morphometric measurements of the cranium in patients with Chiari type I malformation and comparison with the normal population. Acta Neurochir (Wien) 144:165-171, 2002

14. Koenigsberg RA, Vakil N, Hong TA, Htaik T, Faerber E, Maiorano T, et al: Evaluation of platybasia with MR imaging. AJNR Am J Neuroradiol 26:89-92, 2005

15. Kwong Y, Rao N, Latief K: Craniometric measurements in the assessment of craniovertebral settling: are they still relevant in the age of cross-sectional imaging? AJR Am J Roentgenol 196:W421-W425, 2011 
16. Marques SR, Ajzen S, D Ippolito G, Alonso L, Isotani S, Lederman H: Morphometric analysis of the internal auditory canal by computed tomography imaging. Iran J Radiol 9:71-78, 2012

17. McRae DL, Barnum AS: Occipitalization of the atlas. Am J Roentgenol Radium Ther Nucl Med 70:23-46, 1953

18. Mehta VA, Amin A, Omeis I, Gokaslan ZL, Gottfried ON: Implications of spinopelvic alignment for the spine surgeon. Neurosurgery 70:707-721, 2012

19. Rojas CA, Bertozzi JC, Martinez CR, Whitlow J: Reassessment of the craniocervical junction: normal values on CT. AJNR Am J Neuroradiol 28:1819-1823, 2007

20. Saralaya VV, Murlimanju BV, Vaderav R, Tonse M, Prameela MD, Jiji PJ: Occipital condyle morphometry and incidence of condylus tertius: phylogenetic and clinical significance. Clin Ter 163:479-482, 2012

21. Smith JS, Shaffrey CI, Abel MF, Menezes AH: Basilar invagination. Neurosurgery 66 (3 Suppl):39-47, 2010

22. Smoker WR: Craniovertebral junction: normal anatomy, craniometry, and congenital anomalies. Radiographics 14:255-277, 1994
23. Yoshida G, Yasuda T, Togawa D, Hasegawa T, Yamato Y, Kobayashi S, et al: Craniopelvic alignment in elderly asymptomatic individuals: analysis of 671 cranial centers of gravity. Spine (Phila Pa 1976) 39:1121-1127, 2014

\section{Author Contributions}

Conception and design: all authors. Acquisition of data: Joaquim, Batista, Mathias, Ghizoni. Analysis and interpretation of data: Joaquim, Batista, Fernandes. Drafting the article: Joaquim, Tedeschi. Critically revising the article: Joaquim, Batista, Mathias, Fernandes, Ghizoni. Reviewed submitted version of manuscript: all authors. Approved the final version of the manuscript on behalf of all authors: Joaquim. Administrative/technical/ material support: Joaquim. Study supervision: Joaquim, Tedeschi.

\section{Correspondence}

Andrei F. Joaquim, Department of Neurology, Neurosurgery Division, State University of Campinas (UNICAMP), São Paulo, 13087-460, Brazil.email: andjoaquim@yahoo.com. 